\title{
Mulheres gestoras: caracterizando seu perfil em cooperativas agrícolas
}

\author{
Woman management: characterizing their profile in agricultural cooperative
}

\begin{abstract}
Resumo
Esta pesquisa analisar as características das mulheres gestoras nas cooperativas da cadeia produtiva da soja de Dourados/MS e suas tendências e ações empreendedoras nestas organizações. Foram identificadas quatro cooperativas atuantes onde foram realizadas entrevistas com sete mulheres. Os dados indicam que em relação ao perfil empreendedor, as mulheres gestoras da cadeia de soja de Dourados/MS possuem tendência ao tipo Gerente Tradicional e ao Intraempreendedor. E os mandamentos que caracterizam as principais ações empreendedoras são "seja leal às suas metas, mas realista quanto às maneiras de atingi-las" $e$ "honre seus patrocinadores". Constatase que o perfil empreendedor predominante alinha-se com aqueles que estão mais próximos ao perfil feminino de gestão, caracterizado por interdependência, compaixão, empatia, franqueza emocional, criatividade, democracia.
\end{abstract}

Palavras-chave: Cooperativas, Gênero, Gestão.

\begin{abstract}
This paper aims to analyze the characteristics of female managers in cooperatives of the soy production chain of Dourados/MS and their tendencies and entrepreneurial activities in these organizations. It was identified four cooperatives operating with the soy product in Dourados/MS. In those companies interviews were carried out and applied questionnaires with seven women. Some of the categories of preliminary analysis are: number of women managers; features personal, professional, academic and entrepreneurial training; in management, the commandments and trends with which they identify. The data indicated that in relation to managing women entrepreneur profile of Golden soy/MS have tendency to Traditional Manager and the Intra entrepreneur type. The commandments that characterize the main entrepreneurial actions are "be loyal to their targets, but realistic about the ways to achieve them" and "honor your sponsors". Concluding the predominant entrepreneur profile aligns itself with those who are closest to the female management profile, characterized by interdependence, compassion, empathy, emotional honesty, creativity, democracy.
\end{abstract}

Keywords: Gender, Cooperatives Management.

Erlaine Binotto ${ }^{1}$, Manoela Morais², Elisabete Stradiotto Siqueira ${ }^{3}$, Alesandra Stefanello e Ludimylle Alves Apolinário $^{5}$ ${ }^{1}$ Universidade Federal da Grande Dourados; Rua General Osório, 2125/202 - Jardim América, CEP: 79803060; Dourados, Brasil - e-binotto@uol.com.br

${ }^{2}$ Universidade Federal da Grande Dourados; Dourados, Brasil

${ }^{3}$ Universidade Federal Rural do Semi-Árido; Mossoró, Brasil

${ }^{4}$ Centro Universitário Franciscano; Santa Maria, Brasil

${ }^{5}$ Universidade Federal da Grande Dourados; Dourados, Brasil 


\section{Introdução}

$\mathrm{A}$ s cooperativas agrícolas estão passando por adequações em suas estratégias, diante da realidade de mudanças constantes no mercado competitivo, uma vez que foram criadas e cresceram no período em que predominava a agricultura tradicional, ou seja, um período de maior estabilidade. Para fazer frente à nova realidade, as mulheres buscaram se profissionalizar no que se refere à administração e às relações com os seus associados e se adaptar às regras do mercado.

Dessa forma, a cooperativa é vista hoje como uma ferramenta de desenvolvimento de muitos setores, pois oferece condições para o seu cooperado progredir com base em informações e orientações. As cooperativas têm tido sucesso em algumas áreas, por permitirem aos produtores atuarem conjuntamente e controlarem os ativos enquanto buscam poder econômico e político por meio dos seus membros (STEFANSON; FULTON, 2012).

A representatividade econômica e social do cooperativismo no Brasil é evidente pela contribuição que traz em termos da produção e também por ser responsável pela interiorização do desenvolvimento social, consequentemente, contribuindo para diminuir o êxodo em direção aos grandes centros urbanos (OCB, 2012).

Mauget (1996) afirma que os crescentes desafios na gestão das cooperativas decorrem da globalização dos mercados e da pressão exercida pelos concorrentes, criando um ambiente pouco favorável. A complexidade se torna maior para as cooperativas pelas dificuldades administrativas próprias desse tipo de organização, que limitam a flexibilidade quanto à utilização de recursos financeiros e o rápido redirecionamento das estratégias.

No contexto da gestão das cooperativas, encontramse muitas mulheres desempenhando diferentes papéis. Ao analisar a história da mulher na sociedade, entendese que sua participação deu-se muito recentemente, a começar pelo fato de só ter adquirido o direito ao voto em 1917. Até esta data a luta iniciada pelo médico e intelectual baiano César Zama, em 30 de setembro de 1890, recebeu como resposta em 27 de janeiro de 1891, que a "A maioria do Congresso Constituinte, apesar da brilhante e vigorosa dialética exibida em prol da mulhervotante, não quis a responsabilidade de arrastar para o turbilhão das paixões políticas a parte serena e angélica do gênero humano". O que dizer então de sua entrada no mercado de trabalho?

Madruga et al. (2001) apresentam uma retrospectiva que evidencia as características gerenciais femininas, destacando: humildade, estabilidade emocional, objetividade, paciência, auto renúncia, intuição.

Contudo, para os mesmos autores, apesar de todos esses valores, reconhecidos como necessários para a gestão contemporânea, a inserção da mulher no campo gerencial ainda encontra uma série de limites. No campo organizacional destaca-se o limite hierárquico, ou seja, ela pode ascender, em alguns casos, até certo ponto, contanto que seu superior imediato seja um homem, mostrando que, ao mesmo tempo em que a sociedade do conhecimento requer características de flexibilidade, inter-relacionamento, criatividade, valores reconhecidos como predominantemente femininos, as oportunidades de ascensão a cargos gerenciais ainda são muito restritas para as mulheres, conforme pode ser evidenciado:

As mulheres ganham menos que os homens independentemente do setor de atividade econômica em que trabalhem. No ramo da educação, saúde e serviços pessoais,_espaço de trabalho tradicionalmente feminizado, em 2007, por exemplo, encontraremos $1 / 4$ dos trabalhadores e $11 \%$ das trabalhadoras ganhando mais de 5 Salários mínimos. Comparativamente a 2002, constata-se que diminuiu o número de trabalhadores de ambos os sexos com ganhos naquela faixa de remuneração (ganhavam mais de 5 SM $30 \%$ deles e $15 \%$ delas), corroborando a persistência da queda nos rendimentos do trabalho nos últimos cinco anos da série (FUNDAÇÃO CARLOS CHAGAS, 2013, p. s/n)

Para reforçar esse aspecto, Lima, Lucas e Fisher (2011) afirmam que nem mesmo a ampliação da escolaridade entre as mulheres propiciou redução da desigualdade salarial quando comparada aos homens, visto que, de acordo com o Instituto Brasileiro de Geografia e Estatística (IBGE), em 2010, as mulheres com 12 anos ou mais de estudos ainda recebem em media somente $58 \%$ dos rendimentos dos homens com o mesmo nível de instrução (IBGE, 2012).

Frente a esse cenário, Cavalcanti (2001) analisa como as mulheres têm se utilizado do gerenciamento de impressões para produzir uma imagem desejada pelos integrantes das organizações, o que muitas vezes resulta em assumir valores reconhecidos como masculinos anulando suas preferências pessoais.

Mascarenhas, Vasconcelos e Vasconcelos (2004), analisando como se cristalizam valores tipicamente masculinos ou femininos nas lideranças, reconhecem que ainda ocorre de forma contundente a segregação sexual nos empregos, contudo defende que a organização deve fomentar o desenvolvimento da convivência masculina e feminina através da inserção de ambos os gêneros no contexto organizacional, como forma de convivência da diferença como meio de maximizar os potenciais da diversidade.

No que diz respeito ao Estado de Mato Grosso do Sul, os dados apresentam equilíbrio no crescimento demográfico entre os sexos no período de 1991 e 2000, porém a inserção no mercado trabalho da mulher foi maior. Enquanto as mulheres cresceram em $81 \%$, os homens somente $17 \%$, segundo dados da População Economicamente Ativa (PEA) (MARTINS; MARTINS, 2008).

Desta forma, esta pesquisa torna-se relevante na medida em que pretende contribuir para a produção de conhecimento sobre estratégias de ação gerenciais 
e de gênero no aporte do empreendedorismo, para a melhor compreensão da atuação de mulheres nas cooperativas da cadeia produtiva da soja de Dourados/ MS. Assim, reveste-se de importância a ideia central desta pesquisa de caracterizar, identificar, verificar, e analisar o entendimento e comparar a prática da gestão administrativa com as teorias subjacentes. Acredita-se que a realização desta pesquisa poderá contribuir para aumentar o entendimento sobre o assunto, uma vez que seus resultados podem servir de parâmetro e subsidiar o desenvolvimento de novas pesquisas.

A escolha da cadeia produtiva da soja se deve a representatividade do Brasil sendo um dos maiores produtores e exportadores mundiais de soja e seus derivados. Isso gera significativos impactos na economia e no sistema agroindustrial da soja como um todo (MAPA, 2007). A análise desse setor também pode contribuir para percepção de tendências locais e gerais desse tipo de atuação, podendo se constituir, no futuro, no delineamento de outras possibilidades de pesquisa no contexto dessa temática.

Assim, o objetivo deste estudo é analisar as características das mulheres gestoras nas cooperativas da cadeia produtiva da soja de Dourados/MS e suas tendências e ações empreendedoras nestas organizações.

\section{Revisão teórica}

Este tópico trata das seguintes abordagens: empreendedorismo, dando ênfase ao feminino e ao intraempreendedor e ao cooperativismo agropecuário.

\subsection{O empreendedorismo}

O termo empreendedorismo remete a um processo de identificação de oportunidades e criação de algo inovador, sob condições de incerteza, com persistência, visão de futuro e assumindo os riscos envolvidos (HISRICH; PETERS, 2004).

O termo "empreendedor" é derivado da palavra francesa entrepreneur, e foi usado pela primeira vez pelo economista irlandês Richard Cantillon. Segundo o autor "entrepreneur é o indivíduo que assume riscos." Muitos autores tratam do tema Empreendedorismo. Dentre eles, estão Dolabela (2006), Drucker (1996) e Dornelas (2005).

Para Dolabela (2006, p. 29) "o empreendedor é alguém que sonha e busca transformar seu sonho em realidade". Baseado em pesquisas, o autor afirma que o empreendedor é um ser social, produto do meio em que vive, e que todos nascem empreendedores, ou seja, essa é uma característica da espécie humana.

Afirma ainda que "o empreendedor é aquele que faz as coisas acontecerem, se antecipa aos fatos e tem uma visão futura da organização". Cita algumas características dos empreendedores de sucesso, como: são visionários, sabem tomar decisões, são indivíduos que fazem a di- ferença, sabem explorar ao máximo as oportunidades, possuem conhecimento, são apaixonados pelo que fazem, são líderes e formadores de equipes e assumem riscos calculados (DOLABELA, 2006, p. 17).

Analisando os conceitos apresentados, percebe-se que o empreendedor é um indivíduo que encontra oportunidades e faz com que estas sejam aproveitadas, ao máximo, para que possa atingir seus objetivos, mas para isso assume riscos.

Para melhor evidenciar esses aspectos, Filion (2000) acrescenta as características demonstradas por empreendedores bem-sucedidos, sendo estas: experiências em negócios, diferenciação, intuição, envolvimento, líderes, aprendizagem dos seus próprios padrões, valores e cultura de empreendedorismo adquiridos através do contato com um modelo empreendedor durante a juventude, sonhadores realistas (visionários), entre outras que diferenciam um empreendedor de um empreendedor bem-sucedido.

Pinchot III (1989, p. 17 apud Miranda, 2007) destaca dez mandamentos para o intraempreendedor ser atuante e produzir resultados efetivos tanto para si quanto para a organização, características que contemplam o objetivo de que o intraempreendedor deve demonstrar sua atividade na organização: I. Vá para o trabalho a cada dia disposto a ser demitido; II. Evite quaisquer ordens que visem interromper seu sonho; III. Execute qualquer tarefa necessária para fazer seu projeto funcionar, a despeito de sua descrição de cargo; IV. Encontre pessoas para ajudá-lo; V. Siga sua intuição a respeito das pessoas que escolher e trabalhe somente com as melhores; VI. Trabalhe de forma clandestina o máximo que puder - a publicidade aciona o mecanismo de imunidade da corporação; VII. Nunca aposte em uma corrida, a menos que esteja correndo nela; VIII. Lembre-se que é mais fácil pedir perdão do que pedir permissão; IX. Seja leal à suas metas, mas realista quanto às maneiras de atingi-las; $X$. Honre seus patrocinadores.

Segundo Miranda (2007, p. 24) o GEM (Global Entrepreneurship Monitor) é o mais importante órgão que monitora a atividade empreendedora no mundo. Para o GEM (2013, p.3), o empreendedorismo representa qualquer tentativa de criação um novo empreendimento, (...). E importante destacar que o foco principal é o indivíduo empreendedor, mais do que o empreendimento em $\mathrm{si}^{\prime \prime}$.

Os dados do GEM (2013, p.14) apontam que:

"As características recentes da economia brasileira, centrada
no aumento do consumo de massa e no mercado interno,
favorecem o aumento na quantidade dos empreendi-
mentos, porem esses se caracterizam como sendo pouco
inovadores, em atividades econômicas com pequenas
barreiras de entrada e com baixa inserção internacional,
particularmente de serviços".

Especificamente no Brasil, 71,3\% dos empreendedores o fazem por oportunidade, um percentual expressivo. 
Se comparado aos dados de 2012 (69,2\%), houve aumento em todas as regiões, exceto na Região Centro-Oeste, que reduziu de $84 \%$ para $66 \%$. Significa afirmar que 2,5 milhões de brasileiros iniciaram um negócio por identificar uma oportunidade. Ao se considerar a população brasileira, na faixa etária entre 18 a 64 anos, são cerca de 123 milhões de indivíduos. No que diz respeito aos empreendedores, são $32,3 \%$, cerca de 40 milhões de pessoas, ou seja, 21 milhões de empreendedores iniciais e 19 milhões de empreendedores estabelecidos (GEM, 2013).

$\mathrm{O}$ estudo também revelou que, pela primeira vez no Brasil, a proporção de mulheres empreendedoras superou a proporção de homens (52,2\% contra $47,8 \%$ ). Além disso, mais de $80 \%$ das pessoas percebem o empreendedorismo como uma opção de carreira (GEM, 2013).

\subsection{Empreendedorismo feminino}

As barreiras existentes, como o preconceito e a discriminação, dificultam à presença feminina a frente de cargos gerenciais nas empresas, mas este cenário está se modificando tornando considerável e crescente a participação das mulheres em cargos de gestão (GRZYBOVSKI, et al, 2002).

Sobre a inserção feminina no mundo do trabalho, Madruga et al. (2001) apresenta dados que demonstram o crescimento tanto da participação das mulheres nos postos de trabalho, como o aumento da renda. Com base nesses dados, sugerem que esse quadro de participação tem provocado uma reorientação valorativa das organizações. Para a mesma autora, a questão de gênero nas organizações é traduzida ainda de forma estereotipada, ou seja, cristalizam-se características femininas e masculinas de forma antagônica e excludente. Neste entendimento, destaca traços femininos como sendo: interdependência, compaixão, empatia e franqueza emocional. As mulheres seriam mais democráticas, estimulando a participação, e liderando pela inclusão. Apresentam valores como detalhistas, questionadoras, cobrando resultados mais rapidamente, e tornando o ambiente mais dinâmico. Desta forma, as mulheres compartilham decisões e são mais criativas.

Para Miranda (2007), a atuação da mulher no mercado de trabalho, na administração dos seus próprios negócios, conquistando altos cargos nas organizações e nas nações pelo mundo, tem recebido especial atenção pelos pesquisadores. Para demonstrar melhor esse aspecto, Machado (1999) apresenta alguns trabalhos desenvolvidos na década de 80 sobre mulheres empreendedoras que foram pautados na tentativa de definir um perfil psicológico ou comportamental das mulheres empreendedoras. Em termos de características gerais, algumas semelhanças foram encontradas nestes trabalhos, conduzindo às seguintes generalizações sobre a mulher empreendedora:

a) elas têm bom nível educacional, embora com pouco conhecimento de habilidades gerenciais; b) há o predomínio de primogênitas ou filhas únicas, o que os autores explicam como resultado de maior tempo dedicado pelos pais a essas filhas, gerando assim um maior grau de confiança em si próprias, que pode ter contribuído para a iniciativa empresarial;

c) há o predomínio de pais empreendedores, que teriam servido de modelo de identificação para essas empreendedoras;

d) a faixa etária predominante entre elas encontra-se entre 31 a 50 anos de idade.

Outras características que beneficiam o estilo de gestão único das mulheres são destacadas pelos autores Grzybovski, el al, (2002) e Lodi (1999) como: humildade, maior estabilidade emocional, objetividade, paciência, auto renúncia, disposição para operar em ambientes de contrariedade, negociar fazendo menos concessões e inteligência enriquecida pela intuição, sendo estas indispensáveis para a atuação no mundo empresarial contemporâneo.

Vale ressaltar que embora durante grande parte de sua história a mulher tenha desempenhado um relevante papel na sociedade, principalmente voltado para o âmbito familiar, seja na educação dos filhos ou na administração do lar, atualmente sua atuação está mais focada para fora do lar, sugerindo maior reconhecimento e prestígio em função de sua atuação ativa e crescente, especialmente no desempenho de cargos e funções de condução de negócios, podendo ser chamadas de "força econômica do futuro" (O'MEALLY, 2000). O número cada vez maior de mulheres como gestoras acompanha de perto a crescente participação da mulher no mercado de trabalho.

Contudo, conforme Lima, Lucas e Fisher (2011, p.18) tal participação demanda estratégias específicas de se colocar nesses cargos.

Suas carreiras são construídas de forma entrincheirada com foco na preservação do espaço conquistado chegando a formar comunidades. (...) as mulheres adotam como modelo de acesso à identidade no trabalho a estratégia de afinidade seletiva (...) a maior parte das gestoras demonstrou a preferência pelo modelo de solidariedade democrática, primando pela formação de grupos de mulheres que defendem a opinião coletiva, com capacidade de Ação, negociação e discussão das diferenças dentro do próprio grupo.

Jonathan e Silva (2007) ao analisar os conflitos enfrentados pelas mulheres empreendedoras identificam que elas precisam administrar uma série de conflitos entre a vida profissional e pessoal, e, para tanto, desenvolvem estratégias para encontrar equilíbrio entre as diversas demandas. Enfatizam que as empreendedoras buscam auto-realização, e não se sentem culpadas pela dedicação à vida profissional. O enfrentamento dos desafios profissionais geram inovações que transformam o espaço doméstico e profissional e os papeis a eles vinculados

Alguns desses resultados coincidem ao que autores como Dolabela (2006) e Dornelas (2005) citaram em seus 
conceitos de empreendedorismo. Como por exemplo, quando Dolabela (2006) diz que o empreendedor sonha e busca transformar seus sonhos em realidade e que ele é um ser social, produto do meio em que vive, mostrando que ele possui confiança em si próprio e que ele recebe influência do meio em que está inserido; e ainda que o empreendedor de sucesso possui conhecimento, que nos resultados da pesquisa aparece como "um bom nível educacional".

Segundo o GEM (2013) no Brasil, há similaridade na taxa de empreendedores iniciais dentre homens e mulheres, exceto nas regiões Norte, Centro-oeste e Sul, por serem mais elevadas no gênero feminino. Embora os dados desde 2002 tendem a se aproximar em relação aos gêneros feminino e masculino.

Diante cenário da participação da mulher na economia, onde através de suas ações empreendedoras, estas colocam em prática seus saberes, que na maioria das vezes são frutos de uma construção coletiva dos eixos alicerçados entre família, local e cultura (), percebe-se que estes eixos beneficiam-se mutuamente ajudando as empreendedoras a encontrar caminhos que sustentem o equilíbrio e obtenha satisfação, remetendo a multiplicidade de papéis como mais uma das características das mulheres empreendedoras (JONATHAN, 2005; ZOUAIN; BARONE, 2009).

Esses dados confirmam que a mulher brasileira vem a cada dia conquistando seu espaço no mercado de trabalho e que ela tem um papel importantíssimo na nossa economia.

\subsection{O intraempreendedorismo}

Existem dois tipos de empreendedores: aqueles que montam seu próprio negócio e aqueles que trabalham nas empresas desempenhando diversas atividades e papéis dentro das organizações.

Segundo Filion (2004, p. 65), "o intraempreendedor é definido como uma pessoa que desempenha um papel empreendedor dentro de uma organização". Miranda (2007, p.65) concorda com este autor e afirma que "um aspecto relacionado ao empreendedorismo diz respeito ao empreendedor que não é proprietário do negócio, sendo denominado como empreendedor corporativo ou intraempreendedor". Segundo a autora a palavra intraempreendedorismo foi usada pela primeira vez por Pinchot III na década de setenta.

Machado (1999, p. 7) corrobora esta ideia de um papel empreendedor dentro da organização e complementa ao afirmar que o intraempreendedorismo:

\footnotetext{
“trata, de implantar uma metodologia organizacional onde a liberdade de expressão e a comunicação horizontal, através de uma maior delegação de poder aos indivíduos, possa propiciar um senso de criação inovadora através da maior participação dos indivíduos que compõem a estrutura organizacional".
}

Para Filion (2004, p. 67) complementa que "Os empreendedores podem ser descritos como visionários, pessoas que focalizam a realização de uma visão central. Por outro lado, intraempreendedores são visionistas; em outras palavras, pessoas que desenvolvem e realizam visões emergentes e complementares". Segundo o autor, as pessoas visionárias precisam se cercar de pessoas visionistas, que consigam desenvolver e realizar visões complementares.

Hisrich e Peters (2004, p. 61) buscaram mostrar a diferença entre os gerentes tradicionais, empreendedores e intraempreendedores. Enquanto o gerente tradicional procura delegar e supervisionar mais do que se envolver o intraempreendedor se envolve mais e delega menos. $\mathrm{O}$ intraempreendedor e o empreendedor assumem riscos moderados já o gerente tradicional é mais cuidadoso em relação a correr riscos. O gerente tradicional tenta servir somente aos outros, o intraempreendedor busca servir a si próprio, aos clientes e aos patrocinadores.

Nesta mesma perspectiva Nassif, Andreassi e Simões (2011), analisando as diferenças comportamentais entre empreendedores e intraempreendedores, concluem que os empreendedores tem um comprometimento afetivo com a empresa, esperam que o negócio seja bem sucedido e a organização tem centralidade em suas vidas. Os intraempreendedores estão mais preocupados com o reconhecimento profissional e benefícios dele derivados, mas ainda assim declaram que gostam de sua atividade.

Analisando as ideias dos autores verifica-se que o intraempreendedor é aquele que consegue empreender dentro de uma organização, mesmo não sendo o proprietário, e transformar suas ideias em algo concreto. Para isso é necessário que a organização dê todo um suporte que o ajude a conquistar seus objetivos e consequentemente os objetivos organizacionais. Ele costuma correr riscos moderados sempre visando à realização de seus sonhos.

\subsection{O cooperativismo agropecuário}

Culti (2002) afirma que no Brasil as primeiras cooperativas surgiram em 1887 e dedicavam-se a questão do consumo, até 1917 foram criadas outras relacionadas a funcionários de setores públicos e privados, de crédito, agropecuária. A autora afirma que até 1930 essa vertente organizacional caminhou lentamente, sendo que a depressão econômica de 1929 chamou a atenção do governo para o cooperativismo, sendo que em 1932 a atividade foi regulamentada o que proporcionou uma ampliação desse tipo de organização. Em 1945 são criados incentivos materiais e fiscais, que prevalecem até 1966 quando vários deles são retirados, levando ao fechamento de muitas cooperativas. Em 1971, foi criada a Organização das Cooperativas Brasileiras - OCB, órgão nacional de representação das cooperativas existentes no Brasil.

Continua a autora evidenciando as contradições do sistema ao relatar que no governo Collor, ao mesmo tempo que se amplia o cooperativismo ligado a iniciati- 
vas de grande e médio porte, que na prática agem como empresas capitalistas, também se organiza o cooperativismo como instrumento de geração de emprego e renda, passando a incorporar-se como preocupação no FAT-Fundo de Amparo ao Trabalhador. Surgem também o PROGER-Programa de Geração de Emprego e Renda, urbano e rural e emergem as cooperativas de trabalho, fortalecendo o perfil dde cooperativas autogestionárias, chamadas de cooperativismo popular, que busca intercâmbios solidários para propiciar, por esta via, a construção de redes de economia solidária (CULTI, 2002).

Segundo a OCB (2012) o cooperativismo é um movimento, um modelo socioeconômico que une desenvolvimento econômico e bem-estar social em prol de princípios como participação democrática, solidariedade, independência e autonomia, onde pelo menos vinte pessoas são unidas pela cooperação e ajuda mútua, sendo os aspectos legais distintos de outras sociedades.

Esta modalidade organizativa conta com 6.603 cooperativas distribuídas em 13 ramos de atividade, gerou 321 mil empregos diretos em 2012, tem 11 milhões de associados a cooperativas filiadas ao sistema OCB e envolvem 44 milhões de brasileiros na atividade (DIAS JUNIOR, 2013).

Especificamente em relação ao cooperativismo agropecuário, Dias Junior (2013) afirma que são 1.561 organizações no ramo agropecuário, com 1.006.197 produtores rurais, agropastoris e de pesca associados, gerando 164.223 empregos diretos em 2012, com uma participação de $48 \%$ na produção agropecuária nacional, $21 \%$ da capacidade estática de armazenamento de grãos nacional, e com $76 \%$ das famílias (agricultura familiar), cadastradas no Ministério do Desenvolvimento Agrário, associadas a cooperativas do Sistema OCB. Tais dados revelam a magnitude desse setor.

A cooperação constitui um método de ação pelo qual os indivíduos, familiares, membros que possuem interesses comuns constituem um empreendimento, no qual, os direitos são todos iguais e os resultados alcançados são repartidos aos integrantes na proporção de sua devida participação (XAVIER; ANDION, 2010).

Segundo dados da OCB/MS (Organização das Cooperativas Brasileiras no Mato Grosso do Sul, 2012), as cooperativas podem ser classificadas em treze ramos. No estado do Mato Grosso do Sul encontram-se apenas sete destes ramos que são: agropecuário, crédito, saúde, trabalho, infraestrutura, transporte e educacional, destacando que as cooperativas movimentam cerca de 9\% do PIB do estado.

O setor agropecuário apresenta grande destaque no cenário das cooperativas, tanto para o país como para o próprio estado, visto que, este ramo representa $40 \%$ das cooperativas, com produções de soja, algodão, ovos, suínos e milho. Para o estado do Mato Grosso do Sul os empreendimentos das cooperativas agropecuárias produzem $80 \%$ do algodão, $50 \%$ do milho e $40 \%$ da soja do estado (OCB/MS, 2012).
Quanto aos serviços prestados pelas cooperativas agropecuárias para seus associados, elas caracterizamse pelo recebimento, comercialização, armazenamento, industrialização, além da assistência técnica, educacional e social, sendo essa prestação de serviço de suma importância, pois as cooperativas participam de toda cadeia produtiva - desde o preparo da terra até a industrialização e comercialização (OCB/MS, 2012).

\section{Metodologia}

O delineamento da pesquisa foi teórico-empírico e de campo no contexto das cooperativas da cadeia produtiva da soja de Dourados/MS. Para tanto, a pesquisa foi exploratória, com método qualitativo. A população refere-se a todas as doze gestoras integrantes das cooperativas em estudo, compreendendo o período pesquisado. Esta escolha foi intencional, de acordo com os objetivos da pesquisa. Para a realização da coleta de dados foram utilizadas entrevistas semiestruturadas.

O procedimento inicial de pesquisa foi à consulta ao site OCB/MS e a identificação das cooperativas agrícolas situadas em Dourados. Foram identificadas quatro cooperativas atuantes com o produto soja na cidade.

Após, foi realizado um levantamento de dados junto às cooperativas envolvidas e também outras fontes que possibilitassem tal identificação. De posse dessas informações foi efetuado um contato inicial, explicado o objetivo da pesquisa e solicitado a participação das cooperativas. Foram agendadas entrevistas com aquelas mulheres que possuem cargos de gestão que apresentavam maior representatividade quanto aos objetivos da pesquisa e se constituam em respondentes chaves. As entrevistas foram aplicadas no total de sete mulheres que aceitaram participar. Nesta etapa foi realizada uma entrevista individual, com base em uma pauta ou roteiro, composta por questões abertas e estruturadas e foram entregues formulários impressos para que as mesmas respondessem. A última parte da pesquisa foi comparar a pesquisa de campo com o que se revela na literatura de gestão organizacional, no sentido de amparar questões teóricas de importância para a literatura do tema.

Sendo assim, algumas das categorias de análise preliminar são: número de mulheres gestoras; características pessoais, profissionais, de formação acadêmica e empreendedora; no gerenciamento, os mandamentos e tendências com os quais se identificam.

\section{Resultados e discussões}

Neste tópico serão apresentados o perfil das cooperativas e das mulheres participantes da pesquisa, bem como as tendências e ações empreendedoras das mulheres atuantes nas cooperativas. 


\subsection{Perfil das cooperativas participantes da pesquisa}

Em relação às quatro cooperativas atuantes com o produto soja na cidade do Dourados/MS:

A primeira cooperativa tem origem no estado do Paraná e atua na cidade há cerca de 10 anos, possui cinco mulheres entre seu quadro funcional e cerca de 247 cooperados cadastrados.

A segunda cooperativa foi fundada na cidade de Dourados/MS, há cerca de 19 anos, possui 4 mulheres entre seus funcionários e cerca de 132 cooperados cadastrados, sendo de 80 à 90 cooperados ativos.

A terceira cooperativa tem origem no estado do Paraná e atua na cidade a cerca de 4 anos, possui duas mulheres entre seus funcionários e 29 cooperados cadastrados.

A quarta cooperativa foi fundada na cidade de Dourados/MS, há cerca de 10 anos, possui uma mulher entre seus funcionários e 50 cooperados cadastrados.

Destacando o fato das cooperativas ainda possuírem grande número de clientes ao invés de cooperados, durante as entrevistas realizadas foi salientada a dificuldade de tornar os cooperados fiéis às cooperativas, devido principalmente à concorrência existente. Salientando assim a importância de passar informações sobre os benefícios da cooperativa aos cooperados cadastrados.

\subsection{Perfil das mulheres participantes da pes- quisa}

As sete mulheres entrevistadas que ocupam cargos de gestão nas cooperativas da cadeia produtiva da soja de Dourados/MS possuem idade entre 18 e 52 anos, destas $43 \%$ são casadas, $43 \%$ são solteiras e $14 \%$ são divorciadas. Foi constatado um bom nível educacional entre as respondentes, sendo que, $58 \%$ são graduadas, $14 \%$ possuem pós-graduação, $14 \%$ estão graduando-se e $14 \%$ possuem nível técnico, as respondentes são formadas em cursos como: Administração, Pedagogia, Educação Física, Ciências Contábeis e Pós-Graduação Lato-Sensu em Contabilidade Gerencial, além de Técnico em Contabilidade. Em relação aos cargos ocupados há atuação nos diferentes setores, sendo que $43 \%$ são responsáveis pelo setor financeiro, $43 \%$ são auxiliares administrativas e $14 \%$ atuam no setor contábil.

Com relação aos estudos, $71 \%$ das respondentes afirmaram terem sido boas alunas e que gostavam de estudar, $14 \%$ afirmaram que no primeiro ano de faculdade não se dedicavam totalmente, mas mudaram o comportamento e integraram-se a partir do $2^{\circ}$ ano e $14 \%$ afirmaram não gostarem de estudar e o motivo era o fato do curso ser noturno. A forma pela qual melhor elas aprendem é através de métodos denominados por elas como: "colocando em prática", "por em prática a teoria", "observando", "lendo e convivendo", "lendo, praticando, discutindo".

Quando questionadas sobre a existência de empresá- rios na família $86 \%$ das mulheres respondentes não possui e apenas 14\% afirmaram possuir um irmão empresário no ramo de telefonia e internet. Já em relação à existência de alguma pessoa que estas mulheres considerem como modelo $57 \%$ das respondentes ressaltam não possuir e $43 \%$ afirmam possuir, dentre estes modelos encontram-se: Professor de Contabilidade, Mãe Professora e o Administrador da Cooperativa.

Os dados demonstram que a tendência de maior escolaridade no mercado de trabalho se confirma, conforme indicado por Lima, Lucas e Fisher (2011) e Madruga et al (2001) .

\subsection{Tendências e ações empreendedoras das mulheres atuantes nas cooperativas}

A Tabela, 01 apresenta os dez mandamentos sendo que cada mulher assinalou os mandamentos com os quais se identificava.

Estes mandamentos traduzem ações empreendedoras com as quais as mulheres se identificam, a Tabela 01 mostra destaque para os mandamentos "seja leal à suas metas, mas realista quanto às maneiras de atingi -las", "honre seus patrocinadores" e "encontre pessoas para ajudá-lo". Esses dados corroboram com Dolabela (2006), pois este diz que o empreendedor sonha e busca transformar seus sonhos em realidade e que ele é um ser social, produto do meio em que vive, mostrando que ele possui confiança em si próprio e que ele recebe influência do meio em que está inserido.

Com relação às tendências empreendedoras com as quais as entrevistadas identificam-se é possível destacar: buscam "independência e capacidade de avançar nas compensações corporativas"; possuem envolvimento direto com suas atividades; são cuidadosas em relação aos riscos; quanto ao status preocupam-se com símbolos de status e também não possuem preocupação com símbolo de status tradicionais - desejam a independência; lidam com erros e falhas; quanto às decisões geralmente concorda com os que têm cargo na administração superior; servem a si, aos clientes e aos patrocinadores; quanto ao relacionamento com os outros veem as transações dentro da hierarquia. Tais tendências alinham-se ao estilo de gestão feminino proposto por Madruga et al. (2001).

Este cenário permite afirmar que as mulheres apresentaram afinidade com três características do Gerente Tradicional (HISRICH; PETERS, 2004): é cuidadoso em relação ao risco, tenta evitar erros e surpresas, geralmente concorda com os que têm cargo na administração superior.

Os dados apresentam também proximidade com três características do Intraempreendedor (NASSIF; ANDREASSI; SIMÕES, 2011; HISRICH; PETERS, 2004): buscam independência e capacidade de avançar nas compensações corporativas, sem preocupação com símbolos de status tradicionais, servem a si, aos clientes e aos patrocinadores. 
Tabela 01: Mandamentos com os quais se identificam

\begin{tabular}{|c|c|}
\hline Mandamentos & $\begin{array}{l}\text { Mulheres em cada } \\
\text { categoria }\end{array}$ \\
\hline $\begin{array}{l}\text { Seja leal à suas metas, mas realista quanto às maneiras de atingi- } \\
\text { las. }\end{array}$ & 5 \\
\hline Honre seus patrocinadores & 5 \\
\hline Encontre pessoas para ajudá-lo. & 4 \\
\hline $\begin{array}{l}\text { Execute qualquer tarefa necessária fazer seu projeto funcionar, a } \\
\text { despeito de sua descrição de cargo. }\end{array}$ & 3 \\
\hline Nunca aposte em uma corrida, a menos que esteja correndo nela & 2 \\
\hline Vá para o trabalho a cada dia disposto a ser demitido & 1 \\
\hline Evite quaisquer ordens que visem interromper seu sonho & 1 \\
\hline $\begin{array}{l}\text { Siga sua intuição a respeito das pessoas que escolher e trabalhe } \\
\text { somente com as melhores }\end{array}$ & 1 \\
\hline Lembre-se que é mais fácil pedir perdão do que pedir permissão & 1 \\
\hline $\begin{array}{l}\text { Trabalhe de forma clandestina o máximo que puder - a } \\
\text { publicidade aciona o mecanismo de imunidade da corporação }\end{array}$ & 0 \\
\hline Mandamentos & $\begin{array}{l}\text { Mulheres em cada } \\
\text { categoria }\end{array}$ \\
\hline $\begin{array}{l}\text { Seja leal à suas metas, mas realista quanto às maneiras de atingi- } \\
\text { las. }\end{array}$ & 5 \\
\hline Honre seus patrocinadores & 5 \\
\hline Encontre pessoas para ajudá-lo. & 4 \\
\hline $\begin{array}{l}\text { Execute qualquer tarefa necessária fazer seu projeto funcionar, a } \\
\text { despeito de sua descrição de cargo. }\end{array}$ & 3 \\
\hline Nunca aposte em uma corrida, a menos que esteja correndo nela & 2 \\
\hline Vá para o trabalho a cada dia disposto a ser demitido & 1 \\
\hline Evite quaisquer ordens que visem interromper seu sonho & 1 \\
\hline $\begin{array}{l}\text { Siga sua intuição a respeito das pessoas que escolher e trabalhe } \\
\text { somente com as melhores }\end{array}$ & 1 \\
\hline Lembre-se que é mais fácil pedir perdão do que pedir permissão & 1 \\
\hline $\begin{array}{l}\text { Trabalhe de forma clandestina o máximo que puder - a } \\
\text { publicidade aciona o mecanismo de imunidade da corporação }\end{array}$ & 0 \\
\hline
\end{tabular}

Fonte: Dados da Pesquisa (2013) 
Portanto, podem-se caracterizar as mulheres como possuindo tendência ao tipo Gerente Tradicional e Intraempreendedor.

\section{Conclusão}

O objetivo desta pesquisa as características das mulheres gestoras nas cooperativas da cadeia produtiva da soja de Dourados/MS e suas tendências e ações empreendedoras nestas organizações.

O perfil empreendedor das mulheres gestoras está alinhado com as características femininas de gestão. Mesmo em um setor predominantemente masculino não há, por parte dos gestores, resistência para contratação de mulheres para cargos gerenciais.

A pesquisa mostrou que assim como foi constatado em trabalho realizado por Sampaio (2007) com mulheres do setor produtivo e administrativo em uma empresa do ramo automotivo no Estado do Paraná, na gestão das cooperativas da cadeia de soja apresenta-se uma evidente separação entre as funções consideradas masculinas, como a assistência de campo oferecida, e as ligadas aos relacionamentos humanos, que parecem mais indicadas para as mulheres.

Sampaio (2007) mostrou que é surpreendente o número de mulheres que manifestaram alto grau de insatisfação com relação ao setor administrativo, apesar de ocuparem bons cargos, receberem altos salários, condições privilegiadas de trabalho, possibilidades de intercâmbios, viagens e outras articulações. Marçal et al (2006), em estudo feito com trabalhadores de uma empresa beneficiadora de cabos de aço, complementa afirmando que tanto os trabalhadores do setor de produção, quanto os trabalhadores do setor administrativo apresentaram um perfil comportamental indicativo de estresse, porém as probabilidades dos indivíduos levarem uma vida estressada são maiores no setor administrativo.

Porém, este trabalho teve como foco o setor administrativo das cooperativas da cadeia de soja, onde não se verificou a mesma preocupação existente em relação às condições de trabalho vista no setor produtivo.

Nas cooperativas pesquisadas da cadeia produtiva da soja, não se pôde perceber uma insatisfação das mulheres do setor administrativo, pois em suas respostas apareceram mandamentos como 'Seja leal à suas metas, mas realista quanto às maneiras de atingi-las', 'Honre seus patrocinadores' e 'Encontre pessoas para ajudá-lo' conforme resgatado pelo autor Pinchot III (1989, p. 17 apud MIRANDA, 2007).

Destacando-se também as tendências empreendedoras, segundo o autor Hisrich e Peters (2004, p. 61), que se encaixaram nas mulheres deste setor, as características do Gerente Tradicional e Intraempreendedor.

As limitações encontradas nesse estudo foram: falta de informações cadastrais completas sobre as cooperativas do setor, a falta de materiais e noticias sobre as cooperativas do setor que atuam na cidade.

As sugestões para novos estudos se relacionam ao desenvolvimento de pesquisas que comparem o perfil empreendedor feminino deste setor com o de outros, no sentido de identificar o perfil e as características dos determinados setores, alem de estudos sobre as características de outros ramos de atividades cooperativistas.

\section{Referências}

CAVALCANTI, G. Um estudo sobre gerenciamento de impressões em relação ao gênero feminino. XXV Encontro da ANPAD. Anais.... Campinas / SP, 2001.

CULTI, M.N. O Coopetarivismo popular no Brasil: Importância e Representatividade,. In: Anais... Tercer Congreso Europeo de Latinoamericanistas, em Amsterdam-Holanda, 3-6 de julho de 2002.

DIAS JUNIOR, P.C. . Coopetarivismo Agropecuário - Câmara Temática de Assuntos Agropecuários, 2013. Disponível em: www.agricultura.gov.br/arq editor/file/...agropecuarios/.../app_ocb.pdf. Acesso em: 04 set. 2014 .

DOLABELA, Fernando. O segredo de Luísa. -- 30. ed. rev. e atual. -- São Paulo : Editora de Cultura, 2006.

DORNELAS, J. C. A. Empreendedorismo: Transformando ideias em negócios. 2. ed. Rio de Janeiro: Elsevier, 2005.

DRUCKER, Peter F. Sociedade pós-capitalista. 5.ed. são Paulo: Pioneira, 1996.

FILION, L. J.. Empreendedorismo e Gerenciamento: processos distintos, porém complementares. RAE Light. v. 7, n. 3, p. 2-7, Jul./Set. 2000.

Entendendo Os Intraempreendedores Como Visionistas. Revista de Negócios, Blumenau, v. 9, n. 2, p. 65-80, abril/junho 2004.

FUNDAÇÃO CARLOS CHAGAS. Ganhos dos homens e ganhos das mulheres, Séries históricas Disponível em: $<$ http://www.fcc.org.br/ bdmulheres/serie8.php?area $=$ series $>$. Acesso em: 03 set. 2013.

\section{GLOBAL ENTREPRENEURSHIP MONITOR}

(GEM). Empreendedorismo no Brasil.

Disponível em: <file://C:/Users/Erlaine/

Downloads/Pesquisa+GEM+2013+-

+ Relat\%C3\%B3rio+Executivo.pdf. Acesso em: 20 out. 2013. 
GRZYBOVSKI, D.; BOSCARIN, R.; MIGOTT, A. M. B.. Estilo Feminino de Gestão em Empresas Familiares Gaúchas. RAC - Revista de Administração Contemporânea. v. 6, n. 2, p. 185-207 Maio/Ago. 2002.

HISRICH, R. D.; PETERS, M. P. Empreendedorismo. $5^{\mathrm{a}}$ ed. Porto Alegre: Bookman, 2004.

\section{INSTITUTO BRASILEIRO DE GEOGRAFIA E} ESTATÍSTICA (IBGE), disponível: http://www.ibge. gov.br/home/estatistica/pesquisas/pesquisas.php. Acesso. 20 jun. 2012.

JONATHAN, E.G.; SILVA, T.M.R. Empreendedorismo Feminino: Tecendo a trama de demandas conflitantes. Psicologia \& Sociedade 19 (1), 77-84, jan/abr - 2007.

JONATHAN, Eva Gertrudes. Mulheres Empreendedoras: Medos, Conquistas e Qualidade de Vida. Psicologia em Estudo, Maringá, v. 10, n. 3, p. 373-382, set./dez. 2005.

LIMA, L.C.; LUCAS, A.C.; FISHER, A.L. A Construção da identidade profissional de mulheres gestoras em empresas de médio e grande porte. Revista Pensamento \& Realidade, Ano XIV, v. 26, n. 2, p. 1-19, 2011.

LODI, J. B. Fusões E Aquisições: O Cenário Brasileiro. Rio DE Janeiro: Campus, 1999.

MACHADO, H.V. Tendências do comportamento gerencial da mulher empreendedora. Anais.... XXIII Encontro da ANPAD. Foz do Iguaçú / PR, 1999.

MADRUGA, L.R.R.G., GOMES, C.M., FLEIG, D.G., ALTISSIMO, J.C., COSTA, V.F. A valorização da mulher no contexto do trabalho: contradições e evidências identificadas na realidade atual. XXV Encontro da ANPAD. Anais.... Campinas / SP, 2001.

MARÇAL, M A; SOARES, B B F N; CALIXTO, C H C; MASSOTE, R A. Estudo comparativo do nível de estresse do setor administrativo e do setor de produção de uma empresa beneficiadora de cabos de aço. III FISIOTRAB Congresso Brasileiro de Fisioterapia do Trabalho, Curitiba, 2006. Disponível em: < http://www. nersat.com.br/wp-content/uploads/2011/02/ Estudo_Comparativo_do_N\%C3\%ADvel_de_ Estresse_do_Setor_Administrativo_e_do_Setor_ de_Produ\%C3\%A7\%C3\%A3o_de_uma_Empresa_ Beneficiadora_de_Cabos_de_A\%C3\%A7o.pdf $>$. Acesso em: 23 set. 2012.
MARTINS, G. I. V.; MARTINS, C. I. D., Grandes oportunidades para pequenos negócios em Mato Grosso do Sul: estudo de tendências, produção e potencial de consumo. 1.ed. - Campo Grande, MS: Editora Visão: SEBRAE/MS, 2008.

MASCARENHAS, A.O.; VASCONCELOS, F.C.; VASCONCELOS, I.F.G. Batom, pó de arroz e microchips - o falso paradoxo entre as dimensões masculina e feminina nas organizações e a gestão da diversidade. In: VASCONCELOS, I., VASCONCELOS, F. (orgs.), Paradoxos organizacionais - uma visão transformacional. São Paulo: Thomson Learning, 2004.

MAUGET, R. Evolução das Cooperativas Francesas nos Últimos Trinta Anos. Tradução Evelyne Zysman, 1996.

\section{MINISTÉRIO DA AGRICULTURA, PECUÁRIA E} ABASTECIMENTO (MAPA). Cadeia produtiva da soja. Secretaria de Política Agrícola, Instituto Interamericano de Cooperação para a Agricultura; coordenador Luiz Antonio Pinazza. - Brasília: IICA: MAPA/SPA, 2007.

MIRANDA, Cristina Maria Schmitt. Empreendedorismo Feminino na Universidade Regional de Blumenau. 2007. 138f. Dissertação (Mestrado em Administração) - Universidade Regional de Blumenau, Blumenau, 2007.

NASSIF, V.M.J.; ANDREASSI, T. ; SIMÕES, F. Competências empreendedoras: já diferenças entre empreendedores e intraempreendedores? Revista de Administração e Inovação, São Paulo, v. 8 n.3, p. 33-54, jul/set-2011.

O'MEALLY, N. B. Fostering women's entrepreneurship: education, management raining and societal values. CONFERENCE ON WOMEN ENTREPRENEURS IN SMEs: Realising the Benefits of Globalisation and the Knowledge-based Economy, 2. 2000, Paris. Anais... Paris: [s.n.], 2000.

\section{ORGANIZAÇÃO DAS COOPERATIVAS}

BRASILEIRAS (OCB) Disponível em: <http://www. ocb.org.br/site/cooperativismo/index.asp >. Acesso em: 10 Jun. de 2012.

\section{ORGANIZAÇÃO DAS COOPERATIVAS} BRASILEIRAS NO MATO GROSSO DO SUL (OCB/ MS) Disponível em: <http://www.ocbms.org.br/ noticias>. Acesso em: 15 Jul. de 2012.

SAMPAIO, D. de F.. Relações de gênero na indústria automotiva: A problemática da divisão sexual 
do trabalho e da visão essencializada da mulher - Um estudo de caso. Dissertação (Mestrado em Sociologia) - Universidade Federal do Paraná, Curitiba, 2007.

STEFANSON, B.; FULTON, M. New Generation Cooperatives: responding to changes in agriculture, Centre for the Study of Co-operatives, 1997.

Disponível em: <http://coop-studies.usask.ca/>. Acesso em: 5 de Abr. de 2012.

XAVIER, M. L. B.; ANDION, C.. Análise comparada do associativismo e cooperativismo no Brasil e na Espanha: correntes predominantes, história e configurações jurídicas. Anais... IV Encontro de Administração Pública e Governança da ANPAD, Vitória / ES, 2010.

ZOUAIN, Deborah Moraes; BARONE, Francisco Marcelo. Small business através do pan - óptico. RAP - Revista de Administração Pública. Rio de Janeiro, p. 425-438, jan./fev. 2009. 